International Journal of Trend in Scientific Research and Development (IJTSRD)

Volume: 3 | Issue: 3 | Mar-Apr 2019 Available Online: www.ijtsrd.com e-ISSN: 2456 - 6470

\title{
Humanoid Robot Moving in Path and Obstacle Avoidance
}

\author{
T. Mariya John M.E., AMIE
}

\begin{abstract}
How to cite this paper: T. Mariya John "Humanoid Robot Moving in Path and Obstacle Avoidance" Published in International Journal of Trend in Scientific Research and Development (ijtsrd), ISSN: 24566470, Volume-3 | Issue-3, April 2019, pp.572-573, URL: http://www.ijtsrd.co $\mathrm{m} /$ papers/ijtsrd228 73.pdf

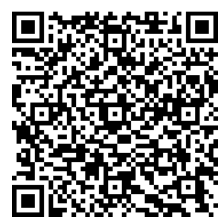

IITSRD22873
\end{abstract}

\section{ABSTRACT}

Humanoid Robot is controlled to move in a path and obstacle avoidance is proposed. The robot avoids obstacles by collecting information about its surrounding environment using sensors. The validity of proposed method is confirmed. The Robot moves in the proposed path with help of Colour sensors and avoids obstacle by Ultrasonic Sensors.

Keywords: Humanoid Robot; Obstacle avoidance; Colour Sensors; Ultrasonic sensors

Copyright (C) 2019 by author(s) and International Journal of Trend in Scientific Research and Development Journal. This is an Open Access article distributed under the terms of the Creative Commons

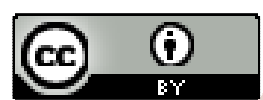
Attribution License (CC BY 4.0) (http://creativecommons.org/licenses/ by/4.0)

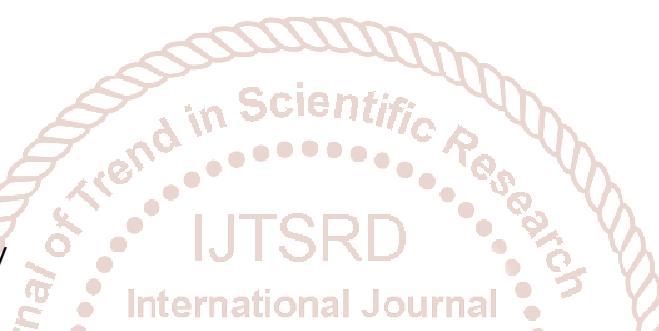

\section{ROBOTICS THEIR REQUIREMENTS IN VARIOUS FIELDS}

Robotics is a branch which functions with various engineering majors like mechanical, electrical, electronic and computer science. It deals with the design, construction, operation, and application of robots, as well as computer systems software program for their control, sensory feedback, and memory for information processing.

\section{PARTS OF HUMANOID ROBOT:}

"The Body" - Mechanical Parts - The physical systems which make up a Skeletal robot. Grids, Gears, Wheels, Screw and nuts are core to this skeletal robot giving a physical design and actuation to Humanoid robot. The Geared Motor is used for the movement of Hand Gears.

"The Nervous System" - Electrical and Electronic Parts Based on electronics, embedded systems, low-level programming and control theory. Encoded Motor is attached to Wheels of Leg. Data cables are used to connect motor mechanical parts and memory, which will be cantered around the control of robot rather than the mechanical design.

"The Brain" - Computer and E-Series Memory - Control code from computer is memorised though software to the ESeries Memory. Colour sensors are fitted near the bottom wheels for path selection and ultrasonic sensors for obstacle avoidance near the head.

\section{MATERIELS REQUIRED:}
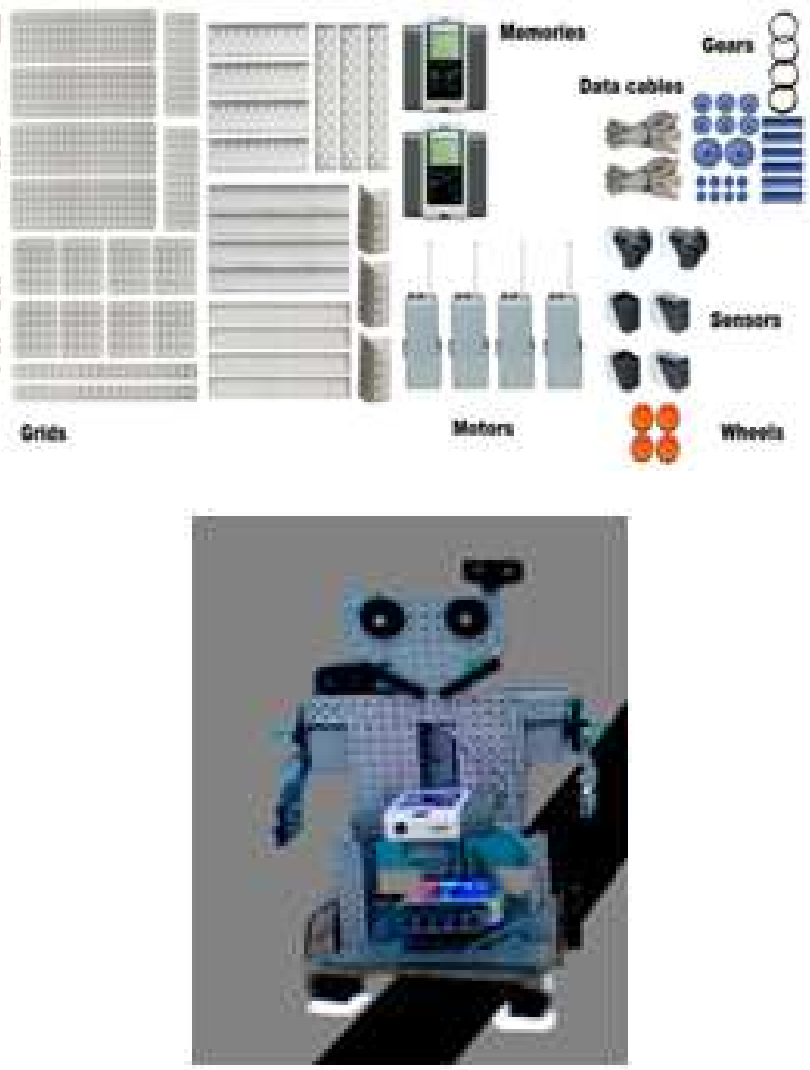

Figure: Humanoid Robot moving in path 


\section{SIMULATION}

Much realistic situation is taken into account, Floor and room layout, initial location of robotics is the start point, The simulations are taken place with a variety of initial conditions of the initial location of robotics and moving and unmoving obstacles.

When obstacles is found before the robot then it moves back delayed 10 unit steps for recovering from the collision situation. A comparative study on the required number of steps (time) for getting the destination from the start point is conducted between with and without path sharing.

\section{SPECIALITY OF THIS ROBOT}

Route planning: path scanning using colour sensors is to autonomously move to the target point under complex and unpredicted environments and avoid obstacles is one of the most fundamental and important capacities of the robot and is also its application basis.

Automatic protection of the robot: With the infrared and ultrasound sensors, etc., the safety of the robot during movement is ensured and effective obstacle avoiding and falling prevention is achieved. The robot is set with an automatic protection mode to automatically enter the protection mode in case of foreign object is near to it.

View in YouTube: https://youtu.be/t6LsO4fB1qE

\section{CONCLUSION}

Control method for moving robot in closed areas based on obstacle avoidance is proposed. Through simulation study, a validity of the proposed method is confirmed. Furthermore, the effect of path selection among robot is confirmed with colour sensors also the effect of obstacle avoidance is confirmed by ultrasonic sensors.

\section{ACKNOWLEDGMENT}

The author would like to thank Mr. Soosai, M.Sc., M.Ed., M.Phil., Head Master, Govt. Boys Higher Secondary School, Alangudi, Pudukkottai District. For his effort and support to conduct simulation studies with Robot.

\section{REFERENCES}

[1] Wang Shaokun, Xiao Xiao, and Zhao Hongwei, "The Wireless Remote Control Car System Based on ARM9," in Instrumentation, Measurement, Computer, Communication and Control, International Conference on , October 2011, pp. 887-890.

[2] Niu Zhigang and Wu Yanbo, "Research on Wireless Remote Control for Coal Mine Detection Robot," in Digital Manufacturing and Automation, International Conference on , December 2010 , pp. 315-318.

[3] Z. Xunyu, P. Xiafu, and Z. Jiehua, "Dynamic collision avoidance of mobile robot based on velocity obstacles," in in Transportation, Me- chanical, and Electrical Engineering (TMEE), 2011 International Con- ference on, 2011, pp. 2410-2413.

[4] [K. Dietmayer, J. Sparbert, and D. Streller, "Model based object classi- fication and object tracking in traffic scenes from range images," in In Proceedings of intelligent Vehicles Symposium, 2001.

[5] G. Hu, W. Tay, Y. Wen, "Cloud robotics: architecture, challenges and applications," IEEE Network, Vol. 26, No. 3, pp. 21-28, 2012.

[6] M. Chen, C. Lai, H. Wang, "Mobile Multimedia Sensor Networks: Architecture and Routing," EURASIP Journal on Wireless Communications and Networking, Vol. 2011.

[7] M. Chen, "MM-QoS for BAN: Multi-Level MAC-Layer QoS Design in Body Area Networks," IEEE Globecom 2013, Atlanta, Georgia, USA, Dec. 9-13, 2013.

\section{AUTHORS PROFILE}

MARIYA JOHN T, He was basically a Diploma holder in Computer Science and Engineering from Kamaraj Polytechnical College, Pazhavalai, Nagercoil, in 1993, He received B.E. from The Institution of Engineers (INDIA) Kerala state centre in 2012, M.E. from Mount Zion College of Engineering and Technology Pudukkottai in 2016, He is a Associate Member of The Institution of Engineers (INDIA). He has worked in Computer Science Departments in various Consultancies, Institutes, and Colleges. He has his own Consern M/s. Mariya Computers and Printers since 2000 in Marthandam, Kanyakumari District., Tamilnadu, India. 